\title{
Arzila, Azila (Maroc)
}

\section{Euzennat et E.B.}

\section{OpenEdition}

Journals

Édition électronique

URL : http://journals.openedition.org/encyclopedieberbere/2605

DOI : 10.4000/encyclopedieberbere.2605

ISSN : 2262-7197

\section{Éditeur}

Peeters Publishers

\section{Édition imprimée}

Date de publication : 1 janvier 1989

Pagination : $943-948$

ISBN : 2-85744-324-2

ISSN : 1015-7344

\section{Référence électronique}

M. Euzennat et E.B., «Arzila, Azila (Maroc) », Encyclopédie berbère [En ligne], 6| 1989, document A283, mis en ligne le 01 décembre 2012, consulté le 13 octobre 2020. URL : http://journals.openedition.org/ encyclopedieberbere/2605; DOI : https://doi.org/10.4000/encyclopedieberbere.2605

Ce document a été généré automatiquement le 13 octobre 2020

(c) Tous droits réservés 


\section{Arzila, Azila (Maroc)}

\section{Euzennat et E.B.}

\section{Euzennat}

1 Petite ville de la côte atlantique, à 40 kilomètres au sud-sud-ouest de Tanger, mentionnée pour la première fois par Ibn Hawkal au $\mathrm{x}^{\mathrm{e}}$ siècle. On a depuis très longtemps rapproché son nom de celui de la Colonia Iulia Constantia Zili dont elle avait, croyait-on, occupé l'emplacement. Aucun témoin marquant de présence romaine n'a cependant été trouvé dans la ville ou à ses abords : la colonia Iulia se trouvait en réalité à 15 kilomètres au nord-est, au Dchar Jedidi, où des ruines importantes signalées dès 1846 par Renou et décrites vingt ans plus tard par Tissot ont été reconnues comme les siennes en 1960 (voir Zili). Il semble que le toponyme, lié au territoire de la colonie autant qu'à son centre urbain, se soit déplacé avec l'habitat. A la fin du Iv siècle ou au début du v viècle, celui-ci abandonna la lagune auprès de laquelle il s'était d'abord fixé et qui s'était progressivement colmatée, pour réapparaître à l'époque islamique en bordure de la mer, à la hauteur du premier mouillage utilisable depuis le cap Spartel, au sud de l'oued el Halou. Il est possible que ce transfert ait eu lieu plus tôt et que le nouvel établissement ait dépendu du gouverneur byzantin de Septem avant de tomber aux mains des Arabes au début du viII ${ }^{\mathrm{e}}$ siècle.

\section{E. B.}

2 En 843, les Normands y font une incursion et brûlent la ville. Une nouvelle destruction a lieu en 936. Trente ans plus tard la ville fut reconstruite par le calife oméïade de Cordoue, El Hakem II, mais elle ne joua qu'un rôle modeste dans l'histoire du Nord du Maroc jusqu'en 1471, année où elle fut prise d'assaut par les Portugais. Ceux-ci en demeurèrent maîtres jusqu'en 1550. Elle devint alors une place importante où la communauté juive s'accrut considérablement lorsque Jean II permit, en 1533, aux juifs portugais expulsés et réfugiés à Safi et Azemmour, de venir s'établir à Arzila. R. Ricard a découvert dans un compte rendu d'interrogatoire de l'Inquisition de Bahia (Brésil) la 
mention d'une synagogue à Arzila. Jusqu'à l'époque contemporaine Arzila eut une communauté juive très active.

Pendant l'occupation portugaise l'insécurité fut constante et Arzila était une place de guerre souvent assiégée. Des expéditions, conduites par les "almoqadem » guides et agents de renseignements, souvent des Maures convertis, étaient envoyées dans le pays djebala et le Rharb pour affirmer la souveraineté du roi. Entre ces périodes de troubles s'intercalent de brèves années de tranquillité au cours desquelles on voit le vizir de Chechaouen et même le sultan de Fès demander au gouverneur d'Arzila l'envoi de médecins réputés. En 1521-1522 une grave épidémie de peste (vraisemblablement la peste bubonique vu les descriptions des chroniqueurs) affaiblit la place. Il y eut 1200 décès, encore avait-on pris la précaution d'embarquer, à destination du Portugal, toutes les femmes et les enfants.

4 Évacuée en 1550, Arzila fut réoccupée en 1578 par les Portugais. Devenue espagnole sous Philippe II, la ville fut cédée au sultan Moulay Ahmed el Mansour en 1588. Une nouvelle tentative d'implantation ibérique a lieu en 1690 mais dès 1692 la ville est évacuée. Ruinée et désertée, Arzila est repeuplée par Moulay Ismaël avec des Berbères du Rif. Cet élément rifain jebala resta prépondérant à l'époque contemporaine. Bombardée par la flotte espagnole en 1860, Arzila fut comprise dans la zone espagnole durant la période du Protectorat. Entre temps la ville avait retrouvé un certain lustre sous le gouvernement de Raïsouli qui s'y fit construire un palais. Moulay Ahmed ben Mohamed Raïsouli s'était rendu célèbre par les rapts d'étrangers suivis de versements de rançons qui l'avaient enrichi; devenu pacha d'Arzila, il exerçait une autorité non négligeable sur une partie des Jebala. Pendant la guerre de 1914-1918, il fut, suivant les circonstances, tantôt un agent de l'Espagne tantôt de l'Allemagne qui l'encourageait dans son ambition de se faire nommer sultan. Chassé d'Arzila par les Espagnols, il entra en concurrence avec Abd el Krim* qui le captura en 1925.

\section{BIBLIOGRAPHIE}

BERNABO RODRIGUES, Anais de Azila, Lisbonne, David Lopes, 2 vol. , 1915 et 1919-1920.

DAMIAO DE GOIS, Les Portugais au Maroc de 1495 à 1521, trad. de R. Ricard, Publ. de l'Inst. des hautes études maroc., t. XXXI, Rabat, 1937.

EUZENNAT M., « Dchar Jedid », Bull, d'archéol. maroc, t. IV, 1960, pp. 534-536.

GOZAlBes BuSto G., « Arcila en la Edad Media », Cuad. de la bibliot. esp. de Tetuan, t. 23-24, 1981, pp. 149-176.

GUEVARA L., Arcila durante la occupacion portuguesa\} Tanger, 1940.

JEAN-LEON L'AFRICAIN, Description de l'Afrique, éd. A. Epaulard, Paris, 1.1, 1956, pp. 260-262.

LENOIR M., « Fouilles de Dchar Jdid 1977-1980 », Bull, d'archéol. maroc, t. XIV, n 16, 1981-1982, p. 215. 
PLINE L'ANCIEN, Histoire naturelle. Livre V, 1-46, $1^{\text {er }}$ partie (l'Afrique du Nord), Paris, éd. J. Desanges, 1980, pp. $87-88$ et n. 6 p. 86 .

RICARD R., « Așīlā », Encyclopédie de l'Islam, 2éd., t. 1, 1960, p. 727.

RICARD R., « Une évocation de la synagogue d'Arzila au XVI e siècle », Hespéris, 1939,pp. 99-100.

RICARD R., « Médecine et médecins à Arzila (1508-1539) », Hespéris, 1939, pp. 171-178.

INDEX

Mots-clés : Antiquité, Géographie, Histoire, Maroc 